\title{
REVIEW
}

\section{The Dipeptidyl Peptidase (DPP)-4 Inhibitors for Type 2 Diabetes Mellitus in Challenging Patient Groups}

David Kountz

To view enhanced content go to www.advancesintherapy.com Received: August 9, 2013 / Published online: November 28, 2013

(C) The Author(s) 2013. This article is published with open access at Springerlink.com

\section{ABSTRACT}

Treating hyperglycemia is a critical aspect of managing type 2 diabetes mellitus (T2DM), but can be especially challenging in patients from vulnerable groups such as those with chronic kidney disease, African Americans, and older people. The dipeptidyl peptidase (DPP)-4 inhibitors are relatively new oral antidiabetes drugs that have been incorporated into treatment algorithms over the past few years and have also been studied in these vulnerable patients. Clinical trials with DPP-4 inhibitors have now been reported for all these patient

Electronic supplementary material The online version of this article (doi:10.1007/s12325-013-0071-y) contains supplementary material, which is available to authorized users.

D. Kountz $(\bowtie)$

Jersey Shore University Medical Center, RutgersRobert Wood Johnson Medical School, 1945 State Route 33, PO Box 397, Neptune, NJ 07754-0397, USA

e-mail: dkountz@meridianhealth.com

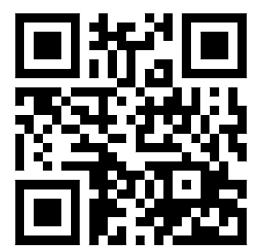

Enhanced content for Advances in Therapy articles is available on the journal web site: www.advancesintherapy.com groups and have demonstrated significant improvements in measures of hyperglycemia, with a good safety profile. Based on the current evidence, it appears that the DPP-4 inhibitors are worthy of consideration not only for the most straightforward patients with T2DM, but also for these vulnerable patients.

Keywords: African American; Chronic kidney disease; Dipeptidyl peptidase-4 inhibitors; Elderly; Type 2 diabetes mellitus

\section{INTRODUCTION}

The prevalence and incidence of diabetes are increasing worldwide, largely due to changing lifestyles characterized by reduced physical activity, rising obesity rates, and an aging population. In the US, diabetes is the leading cause of kidney failure, new cases of blindness, and non-traumatic lower limb amputations, and is a major cause of heart disease and stroke [1]. Diabetes currently affects $8.3 \%$ of the US population, some 25.8 million people [1], and type 2 diabetes mellitus (T2DM) accounts for about $90-95 \%$ of all diagnosed diabetes cases in adults. 
It is well documented that good glycemic control can positively influence much of the morbidity and mortality associated with T2DM [2]. To manage hyperglycemia, expert guidelines recommend treatment to a glycated hemoglobin (HbA1c) level of below 6.5\% or below $7.0 \%$, with recognition of the need for individualization of treatment goals, for example, to minimize the risks of hypoglycemia [2-4]. The percentage of US individuals with self-reported diabetes who achieved an HbA1c level of $<7 \%$ increased from $44 \%$ in $1988-1994$ to $52.5 \%$ in 2007-2010 [5]. Similarly, an observational study of non-insulin-treated patients with T2DM from Spain $(n=2,266)$ indicated that $45 \%$ had suboptimal HbA1c based on the $<7 \%$ criterion [6]. The International Diabetes Management Practices Study (IDMPS) of data from developing regions of Eastern Europe, Asia, and Latin America reported that $36.4 \%$ of participants with T2DM achieved an HbA1c of $<7 \%$ [7]. These data were consistent with those from an observational study in Taiwan in which the percentage of patients achieving the $<7 \%$ goal increased from $32.4 \%$ in 2006 to $34.5 \%$ in 2011 [8]. Taken together, these findings suggest that there has been some success in putting guidelines into practice, but that approximately one-third to one-half of patients still fail to achieve HbA1c levels below 7.0\% [5-8]. Furthermore, the progressive deterioration of $\beta$-cell function, irrespective of pharmacological interventions to treat hyperglycemia, leads to an almost inevitable need for intensification of treatment [2]. There is, therefore, a recognized need for new therapeutic options that are well tolerated over the long term and have a durable effect.

The dipeptidyl peptidase (DPP)-4 inhibitors are relatively new drugs that may help meet the need for these types of treatments, and following extensive testing in phase 3 clinical trials, these agents have now been included in treatment recommendations in all major diabetes guidelines. This review will provide a brief overview regarding the positioning of DPP-4 inhibitors in the context of major clinical guidelines. Furthermore, since the majority of patients in phase 3 trials are relatively young and healthy, an additional objective of this review is to consider the DPP-4 inhibitors for the treatment of T2DM in more vulnerable patient populations, namely those with chronic kidney disease (CKD), African Americans, and older people. Current guidelines for these patients, and the clinical trials conducted with DPP-4 inhibitors in these groups, will be reviewed.

\section{METHODS}

This was a non-systematic review of the literature. A search of English-language literature was performed using PubMed and without imposing any time limitations. Search terms included combinations of the following: 'type 2 diabetes', 'DPP-4 inhibitors', 'chronic kidney disease', 'end-stage renal disease', 'renal impairment', 'African American', and 'elderly'. Articles and abstracts relevant to the subject were included. Bibliographies from retrieved articles were also searched for relevant articles. Additional references known to the author were also included. The analysis in this article is based on previously conducted studies, and does not involve any new studies of human or animal subjects performed by any of the authors.

\section{DPP-4 INHIBITORS}

The DPP-4 inhibitors improve glycemic control mainly via potentiation of the incretin effect, that is, the postprandial augmentation of insulin secretion by the gastrointestinal 
incretin hormones glucagon-like peptide (GLP)1 and gastric inhibitory polypeptide (GIP). Increases in GLP-1 levels appear to account for the majority of the DPP-4 inhibitors' effects [9]. In addition to enhancing glucose-dependent insulin secretion, GLP-1 suppresses glucosedependent glucagon secretion, inhibits gastric emptying, and reduces appetite and food intake [10]. It has long been known that the incretin effect is blunted in patients with T2DM, generating interest in therapies that target the incretin system [10]. Native GLP-1 itself cannot be used in therapy due to its rapid degradation by the DPP-4 enzyme, resulting in a half-life of less than $2 \mathrm{~min}$. Nevertheless, therapeutic approaches for enhancing incretin action have been developed and include degradationresistant GLP-1 receptor agonists, and increasing levels of GLP-1 indirectly by inhibition of DPP-4 [10].

Four DPP-4 inhibitors are approved in the US: sitagliptin (approved 2006), saxagliptin (approved 2009), linagliptin (approved 2011), and alogliptin (approved 2013). Vildagliptin is another DPP-4 inhibitor that has been extensively studied and is currently available in the European Union and Japan. There are also other DPP-4 inhibitors in earlier stages of development that may become available over the coming years. Although all of the DPP-4 inhibitors share the same mechanism of action, they have different chemical and pharmacokinetic properties, which may translate into clinical options with distinct profiles.

\section{Place in Current Guidelines}

In clinical trials, all available DPP-4 inhibitors have been shown to improve glycemic control, with clinically meaningful reductions in HbA1c [11]. Furthermore, they are well tolerated, are associated with a low risk of hypoglycemia, and have a favorable weight profile [11]. As evidence accumulates for their effectiveness, the DPP-4 inhibitors have been incorporated into numerous guidelines available for the management of patients with T2DM. A consensus statement and algorithm issued by the American Association of Clinical Endocrinologists (AACE) in 2013 describes several options for monotherapy and variations of combination therapy [4]. The DPP-4 inhibitors are placed among monotherapy options for patients with an entry level HbA1c of $<7.5 \%$. As with American Diabetes Association (ADA) and European Association for the Study of Diabetes (EASD) recommendations, metformin is recommended as the first-line choice where not contraindicated. The AACE algorithm also places DPP-4 inhibitors as an option for the second component of initial dual or triple therapy in patients with entry HbA1c levels of $\geq 7.5 \%$ or $\geq 9 \%$, respectively. The DPP-4 inhibitors may also be considered as the first component of dual or triple therapy for patients for whom metformin is contraindicated. The detailed AACE guidelines issued in 2011 noted that DPP-4 inhibitors, along with metformin, sulfonylureas, glinides, and thiazolidinediones, are all approved for use in combination with insulin [3]. However, the guidelines also highlight a raised potential for hypoglycemia when a sulfonylurea or a glinide is used with insulin, as well as several adverse effects associated with thiazolidinediones in combination with insulin, suggesting that these combinations should be carefully considered.

The ADA and EASD also issued a position statement on the management of hyperglycemia in T2DM [12]. The ADA/EASD guidelines are less prescriptive, discuss 
advantages and disadvantages of all antidiabetes medicines, and highlight the need for individualization of treatment. In the general recommendations outlined in the guidelines, DPP-4 inhibitors are positioned alongside sulfonylureas, thiazolidinediones, GLP-1 agonists, and insulin, as a second-line add-on to metformin. They are prioritized along with GLP-1 agonists as an add-on to metformin when the goal is to avoid weight gain, and with GLP-1 agonists and thiazolidinediones when the goal is to avoid hypoglycemia. When metformin is not an option for first-line therapy, the ADA/EASD guidelines suggest a sulfonylurea, thiazolidinedione, DPP-4 inhibitor, or GLP-1 agonist.

Among other guidelines, the International Diabetes Federation [13], the National Institute for Health and Clinical Excellence [14], and the US Department of Veterans Affairs/Department of Defense [15], all suggest DPP-4 inhibitors as an alternative add-on to metformin, when a sulfonylurea is contraindicated or when hypoglycemia is a concern.

Guidelines are typically based on randomized trials that recruit the most straightforward patients. In the past, this is known to have led to underuse of new treatments in the very patients who could benefit the most. For example, African Americans are generally not well represented in clinical trials [16], and this, in addition to other factors, resulted in lower use of angiotensin-converting enzyme (ACE)inhibitors (ACEI) for the treatment of hypertension in African Americans [17]. Conversely, therapies should not be used in patients when evidence is lacking. Therefore, in light of a number of recently reported studies, it is worthwhile examining the available evidence for use of DPP-4 inhibitors in vulnerable patient groups.

\section{Use in Patients with Chronic Kidney Disease}

The National Kidney Foundation (NKF) Kidney Disease Outcomes Quality Initiative (KDOQI) defines CKD by the presence of kidney damage or a glomerular filtration rate (GFR) $<60 \mathrm{~mL} /$ $\mathrm{min} / 1.73 \mathrm{~m}^{2}$ for 3 months or more [18]. It also classifies the stages of CKD as ranging between Stage 1 (kidney damage with normal or increased GFR) and Stage 5 (kidney failure). End-stage renal disease (ESRD) is included under Stage 5 of the KDOQI classification and is defined as irreversible decline in kidney function that is severe enough to be fatal in the absence of dialysis or transplantation [18].

Diabetes is considered a major risk factor for CKD, with nearly $40 \%$ of adults with T2DM having some degree of CKD [19, 20]. Furthermore, $44 \%$ of new ESRD cases in the US in 2010 had a primary diagnosis of diabetes [21]. While managing hyperglycemia is a key goal in patients with CKD, glycemic targets and choice of therapy in this patient group warrant special consideration. For example, metformin, normally the first choice of treatment for T2DM, is renally excreted, and decreased kidney function may increase the risk of lactic acidosis with its use. Current prescribing guidelines in the US contraindicate metformin when serum creatinine levels are $\geq 1.4 \mathrm{mg} / \mathrm{dL}$ in women and $\geq 1.5 \mathrm{mg} / \mathrm{dL}$ in men [22]. Furthermore, many other common antidiabetes drugs are renally excreted and have a prolonged half-life in patients with CKD, thereby increasing the risk of hypoglycemia. Recent guidelines for diabetes and CKD state that HbA1c targets of $<7.0 \%$ are not recommended in patients with diabetes who are at risk for hypoglycemia, including those treated with insulin or sulfonylureas and/ or who have advanced CKD. They suggest 
instead extending HbA1c targets above $7.0 \%$ for patients with diabetes who are at risk of hypoglycemia and have clinically significant comorbidities or limited life expectancy [23].

The glucose-dependent stimulation of insulin release by the DPP-4 inhibitors confers a low risk of hypoglycemia [24], suggesting potential value for managing hyperglycemia in patients with T2DM and CKD. Indeed, a number of trials that specifically investigated DPP-4 inhibitors in renally impaired populations have been reported (Table 1) or completed with results anticipated in the near future (Table 2) [25-36]. Efficacy and safety data from the clinical trials reported to date are encouraging, and the DPP-4 inhibitors were generally well tolerated (Table 1). With appropriate caution, the DPP-4 inhibitors can be used in patients with all degrees of renal insufficiency, including ESRD, although dosage reduction is needed for saxagliptin, sitagliptin, and vildagliptin. Linagliptin can be used without adjustment, since it is not renally excreted (Table 3) [37-41].

Individuals with concomitant T2DM and CKD may be receiving an ACEI for management of hypertension because this class of medications may reduce cardiovascular events and protect the kidney [2]. A small increase in the risk of angioedema has been observed in patients taking concurrent ACEI and vildagliptin, but the authors were unable to determine a class effect through review of postmarketing surveillance data and the literature [42]. It is postulated that ACE inhibition shifts the metabolism of the angioedema-associated vasoactive peptides bradykinin and substance $\mathrm{P}$ to the secondary DPP-4 pathway [42, 43]. However, little information is available regarding the clinical relevance and frequency of ACEI and DPP-4 inhibitor interactions [43]. On the other hand, the propensity for drug-drug interactions mediated via the p-glycoprotein (P-gp) intestinal transport system and related to cytochrome P450 3A4 (CYP3A4) metabolism have been well characterized, with some variation among the DPP-4 inhibitors [37-41, 44]. Generally, the DPP-4 inhibitors have limited drug-drug interactions via these mechanisms [37-41, 44]. However, alternatives to strong inducers of CYP3A4 or P-gp (e.g. rifampin) are strongly recommended when linagliptin is to be administered [38]. In addition, a reduction of the saxagliptin dosage to $2.5 \mathrm{mg}$ once daily is recommended when coadministered with strong CYP3A4/5 inhibitors (e.g. ketoconazole) [39].

\section{Use in African Americans}

African Americans are at an increased risk of T2DM, with a prevalence of diabetes approximately double that of the white population [45]. This group also has an increased rate of complications and greater disability from complications, as well as poorer glycemic control and quality of care [46-50]. The pathophysiology of T2DM may be different in African Americans than in other populations, with studies suggesting that insulin resistance is higher in minority populations [51]. There are various theoretical reasons to consider DPP-4 inhibitors in African Americans. First, a small number of studies report racial disparities in GLP-1 levels that may have implications for efficacy of DPP-4 inhibitors in African Americans. Two studies observed that African American adolescents had lower GLP-1 concentrations than white adolescents $[52,53]$. In contrast, an earlier investigation reported that obese African American adults had significantly higher fasting and post-challenge GLP-1 concentrations than obese white adults 


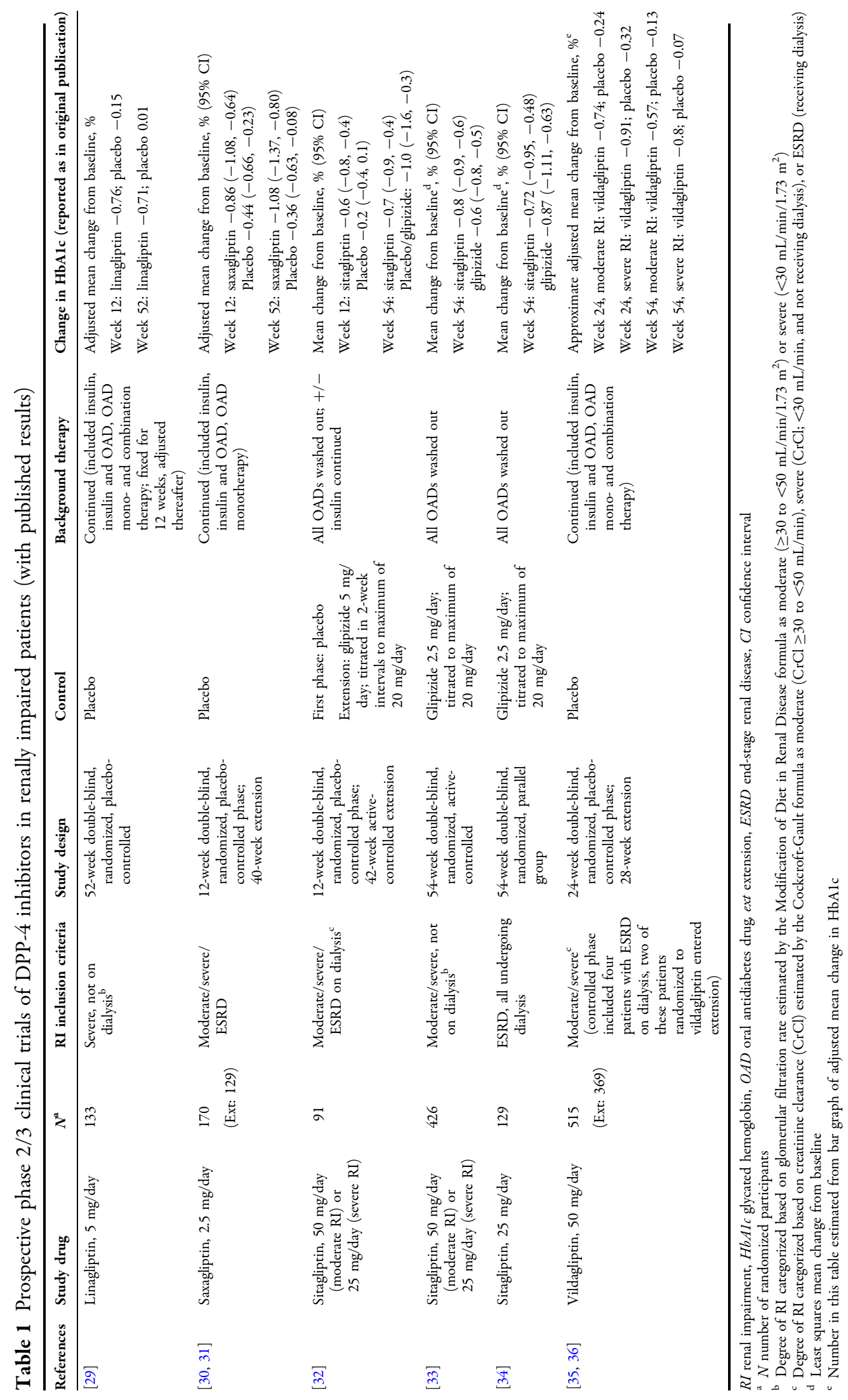




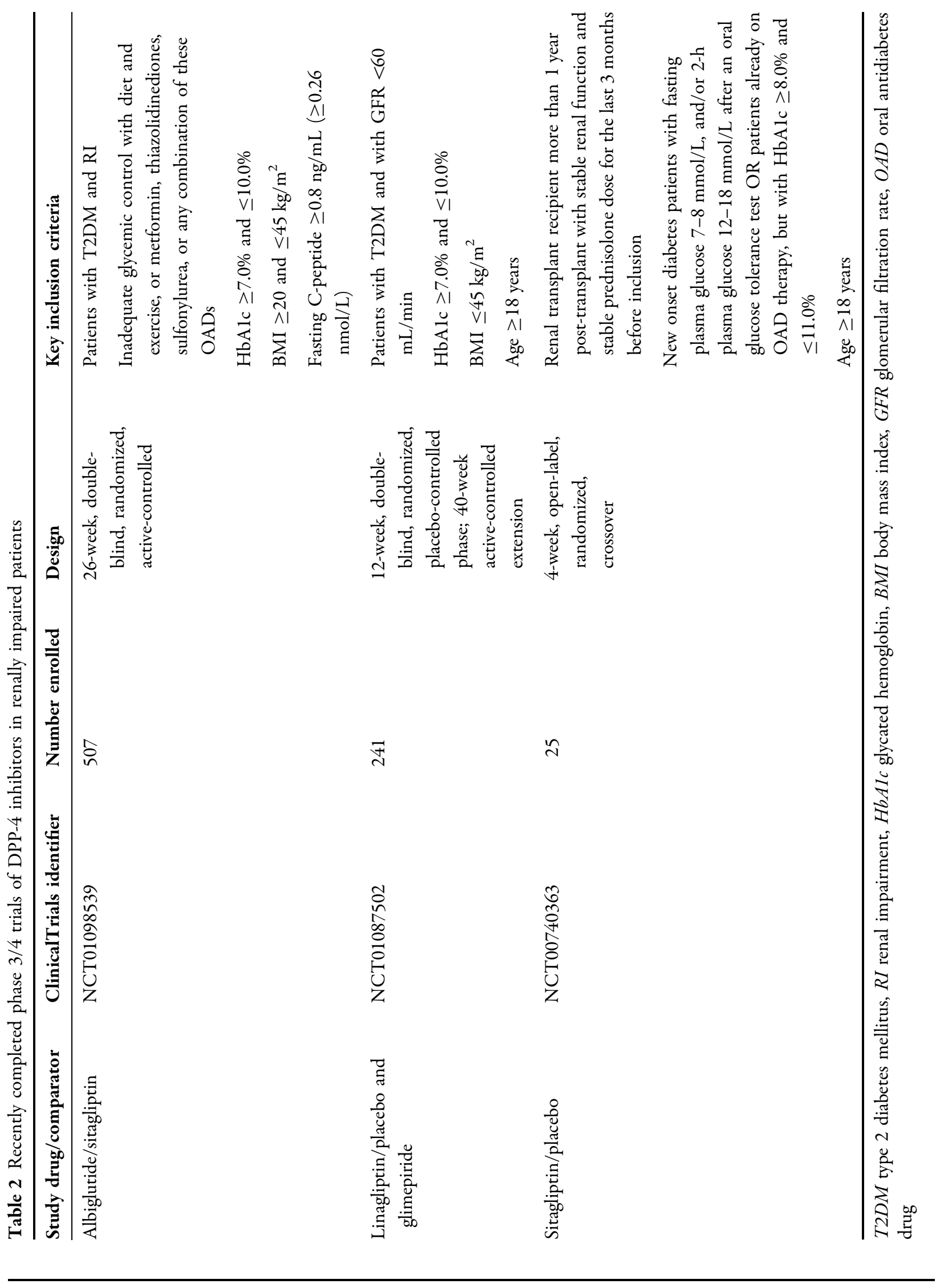


Table 3 Recommended dosing of DPP-4 inhibitors in the presence of CKD

\begin{tabular}{llll}
\hline & First approved & Standard dose & Recommended dose in context of chronic kidney disease \\
\hline Alogliptin [37] & US (2013) & $25 \mathrm{mg}$ once daily & $\mathrm{CrCl} \geq 30 \mathrm{to}<60 \mathrm{~mL} / \mathrm{min}$ (moderate $\mathrm{RI}): 12.5 \mathrm{mg}$ once daily \\
& & & $\mathrm{CrCl}<30 \mathrm{~mL} / \mathrm{min}$ (severe/ESRD): $6.25 \mathrm{mg}$ once daily \\
Linagliptin [38] & US (2011) & $5 \mathrm{mg}$ once daily & $\mathrm{No}$ dose adjustment required \\
Saxagliptin [39] & US (2009) & $5 \mathrm{mg}$ once daily & $\mathrm{CrCl} \leq 50 \mathrm{~mL} / \mathrm{min}$ (moderate/severe/ESRD): $2.5 \mathrm{mg}$ once daily \\
Sitagliptin [40] & US (2006) & $100 \mathrm{mg}$ once daily & $\mathrm{CrCl} \geq 30$ to $<50 \mathrm{~mL} / \mathrm{min}$ (moderate RI): $50 \mathrm{mg}$ once daily \\
& & & $\mathrm{CrCl}<30 \mathrm{~mL} / \mathrm{min}$ (severe/ESRD): $25 \mathrm{mg}$ once daily \\
Vildagliptin [41] & $\mathrm{EU} \mathrm{(2007)}$ & $50 \mathrm{mg}$ twice daily & $\mathrm{CrCl}<50 \mathrm{~mL} / \mathrm{min}$ (moderate/severe/ESRD): $50 \mathrm{mg}$ once daily \\
\hline
\end{tabular}

$\mathrm{CrCl}$ creatinine clearance, $E S R D$ end-stage renal disease, $R I$ renal impairment

[54]. Further studies are warranted to confirm racial differences in GLP-1 levels and to investigate any therapeutic implications.

In the meantime, there are other reasons why DPP-4 inhibitors may be a good option for this population. A significant proportion of African Americans are overweight or obese, with the prevalence of overweight and obesity combined at $76.6 \%$ (69.9\% in men, $82.1 \%$ in women), and the prevalence of obesity at $49.6 \%(38.8 \%$ in men, 58.6\% in women) [55]. Overweight and obesity are risk factors for insulin resistance, and all guidelines therefore recommend losing weight for overweight or obese patients with T2DM [2-4]. In contrast to insulin and some oral antidiabetes drugs that can result in weight gain, the weight-neutral DPP-4 inhibitors may therefore be an appropriate option for patients who are overweight or obese. African Americans are also disproportionally affected by CKD and ESRD $[56,57]$, with the rate of new ESRD cases being 3.4 times higher among this group than among the white population [21]. The presence of renal impairment has implications for diabetes management, but as discussed in the previous section, the DPP-4 inhibitors remain a viable choice in this setting.

Despite the prevalence of T2DM in African Americans, there is limited clinical trial information for this population. While the DPP-4 inhibitors seem theoretically appropriate for use in African Americans with T2DM, this group is characterized by higher HbA1c levels than other populations [58]. With predicted $\mathrm{HbA} 1 \mathrm{c}$ reductions ranging between 0.4 and $1.0 \%$ with this class of drugs [11, 59], monotherapy would likely not be suitable for all patients, although larger reductions are expected in patients with higher baseline HbA1c [60].

Based on composite analyses of available pharmacokinetic data, the prescribing information for all DPP-4 inhibitors state that no dose adjustment is necessary based on race [37-41], but to date only linagliptin has been specifically investigated in African Americans. A phase 1 study (NCT00935220) assessing its pharmacodynamic and pharmacokinetic profile in African Americans with T2DM for 7 days, supported linagliptin $5 \mathrm{mg} /$ day as effective for controlling blood glucose levels [61]. A subsequent phase 3 trial (NCT01194830) evaluated its efficacy and safety in black/African Americans with T2DM over 24 weeks [62]. In this study, 226 patients were randomized to linagliptin or placebo, and HbA1c levels were measured every 6 weeks. A statistically significant and clinically relevant difference 
between treatment groups was found for the change in HbA1c after 24 weeks [placeboadjusted mean change of $-0.58 \%$ (95\% CI 0.91 to $-0.26 \% ; P<0.001)]$, indicating the superiority of linagliptin compared with placebo in reducing HbA1c in black/African American patients [63]. Furthermore, as expected from pivotal trials, linagliptin was well tolerated and weight neutral, with a low rate of hypoglycemic events, confirming its safety profile as well as efficacy in African American patients with T2DM [63].

\section{Use in Older People}

The latest census figures in the US indicate that people aged 65 years and older represent $13.2 \%$ of the population [64], and this proportion is expected to grow to just over $20 \%$ by 2050 [65]. The incidence of T2DM in older people is a major public health concern, and in 2010 almost $27 \%$ of people aged 65 years and older in the US had diabetes [1]. Clinical management of the older patient with T2DM is often challenging as these patients have an increased prevalence of cardiovascular risk factors, diabetes-related complications, and comorbidities such as renal impairment, congestive heart failure, cognitive impairment, and physical disability. Furthermore, they are often prescribed multiple medications, which further complicates treatment strategies and may reduce adherence [66-68]. The older T2DM patient population is, however, a highly heterogeneous group with a broad spectrum of disease duration, life expectancy, and comorbidities. A position statement issued by the International Association of Gerontology and Geriatrics (IAGG), the European Diabetes Working Party for Older People (EDWPOP), and the International Task Force of Experts in Diabetes, recommends that an HbA1c target range of $7.0-7.5 \%$ should generally be aimed for in older patients. The caveat to this statement is that individual comorbidities, and cognitive and functional status, should be considered when determining goals. Furthermore, this position statement highlights hypoglycemia in older people as a highly prevalent and underrecognized disorder with severe consequences such as falls, cognitive impairment, and hospital admission [69].

The heterogeneity of this population is also addressed by the ADA. Their guidelines recommend that the same glycemic targets be applied to otherwise healthy older people as to younger people with diabetes; and a less ambitious target be applied to patients with more complicated conditions that include multiple comorbidities, a high level of functional dependency, and limited life expectancy $[2,70]$.

The DPP-4 inhibitors have generated particular interest for the treatment of older patients with T2DM for a number of reasons, namely their convenient oral dosing, the importance of avoiding hypoglycemia in the elderly, and considerations of declining renal function in this patient group. Indeed, the recent position statement mentioned above states that in selected older patients not at target or where there is poor tolerance to glucose-lowering agents, the use of DPP-4 inhibitors can be considered as second-line therapy [69]. The ADA acknowledges the few side effects associated with DPP-4 inhibitors in the context of their use in older patients; however, it also notes that their costs may be a barrier to some older patients [2]. The prescribing information available for these drugs generally agree that no overall differences in safety or effectiveness were observed between patients aged 65 years and over and younger patients [37-41]. However, 
caution is advised in the context of older patients, who are more likely to have decreased renal function, and dosing adjustments are recommended for all DPPinhibitors, except linagliptin, under these circumstances.

Three studies that prospectively assessed DPP-4 inhibitors in older patients with T2DM have been reported [71-73] (Table 4). A doubleblind, randomized, active-controlled study compared vildagliptin with metformin over 24 weeks in 335 drug-naïve patients with T2DM aged $\geq 65$ years. In this study, $41 \%$ of patients had normal renal function, $57 \%$ had mild renal insufficiency, and less than $2 \%$ had moderate renal insufficiency. The investigation showed that vildagliptin is an effective and well-tolerated treatment option in this group, demonstrating non-inferiority to metformin in terms of glycemic control, but superior gastrointestinal tolerability [71]. The second trial, a double-blind, randomized, placebocontrolled study of sitagliptin over 24 weeks in 206 patients with T2DM aged $\geq 65$ years, concluded that sitagliptin significantly and rapidly improved glycemic control and was well tolerated in this group [72]. This study also included patients with moderate renal insufficiency $(22 \%)$, but excluded those with severe renal insufficiency (estimated creatinine clearance $<35 \mathrm{~mL} / \mathrm{min}$ ). Finally, a randomized, double-blind, placebo-controlled study investigated the efficacy and safety of linagliptin in 241 patients aged $\geq 70$ years with T2DM and insufficient glycemic control despite metformin and/or sulfonylurea and/or insulin therapy [73]. The majority of patients in this study had either normal renal function $(21 \%)$ or mild renal insufficiency (52\%); $26 \%$ of patients had moderate renal insufficiency and less than $2 \%$ had severe renal insufficiency. This study concluded that linagliptin was effective and well tolerated in elderly patients and no safety concerns were identified.

Other pooled analyses, subgroup analyses, and systematic reviews also showed that DPP-4 inhibitors in the older T2DM population were generally effective and well tolerated [74-81]. However, some studies show that when DPP-4 inhibitors are concomitantly administered with insulin or a sulfonylurea, there is an elevated risk of hypoglycemia over the concomitant administration of placebo with insulin or a sulfonylurea [82, 83]. In contrast, a pooled analysis evaluating linagliptin as add-on therapy to basal insulin showed no increased risk of hypoglycemia with the DPP-4 inhibitor [81]. Given the serious consequences of hypoglycemic events in older patients, the combination of a DPP-4 inhibitor with a sulfonylurea is perhaps ill advised; in fact, the IAGG, EDWPOP, and the International Task Force of Experts in Diabetes recommend that sulfonylurea therapy should be avoided in any older patient at risk of hypoglycemia [69].

Interestingly, there is also preliminary evidence that DPP-4 inhibitors are associated with a reduced risk of bone fractures compared with placebo or other treatments [84]. Recent evidence shows that T2DM is an independent risk factor for bone fracture $[85,86]$ and that older people with T2DM are at an increased risk of hip fractures $[87,88]$. Furthermore, clinical trial data suggest that DPP-4 inhibitors may be associated with a lower risk of stroke compared with other therapies [89]. Patients with diabetes have an increased risk of ischemic stroke, a risk that increases in correlation with duration of diabetes [90, 91], therefore posing a particular concern for elderly patients with long-standing T2DM. If confirmed, these risk reductions will provide further compelling reasons to consider DPP-4 inhibitors in older patients. Various prospective studies of glycemic outcomes in 


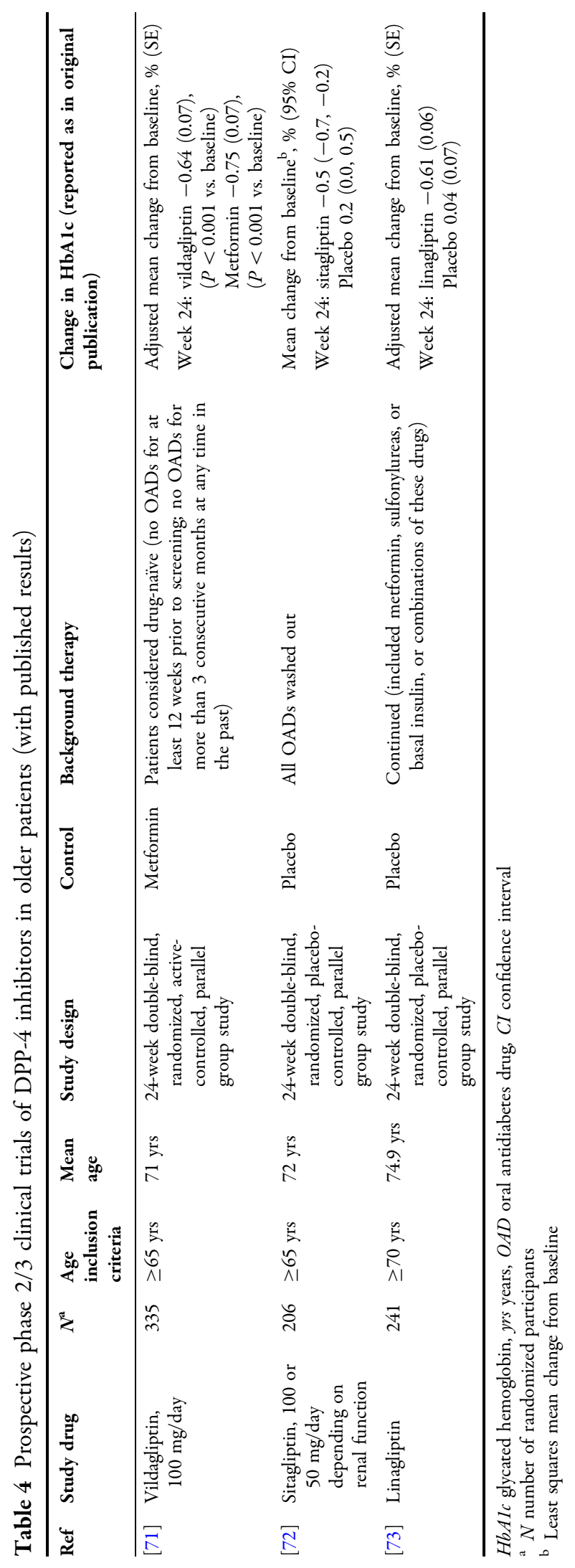




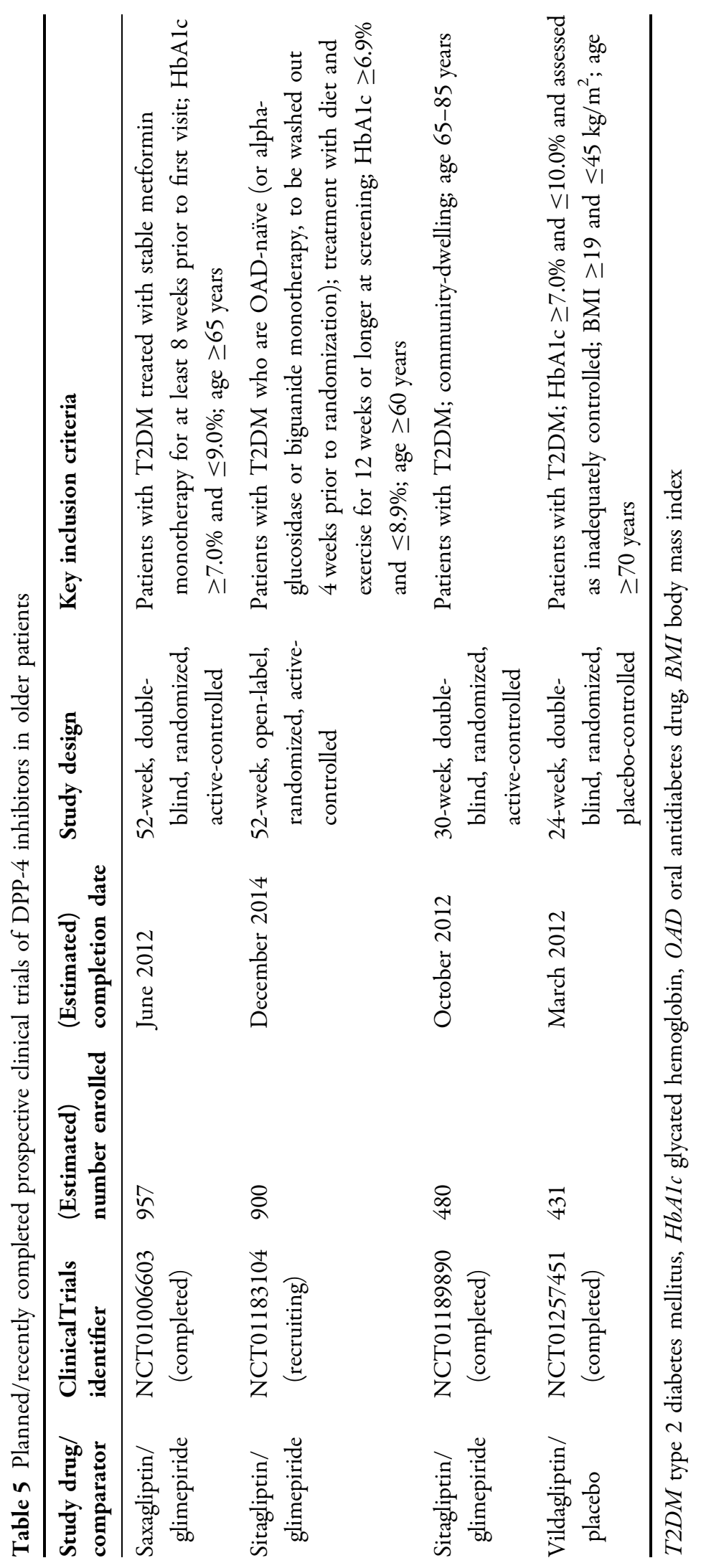




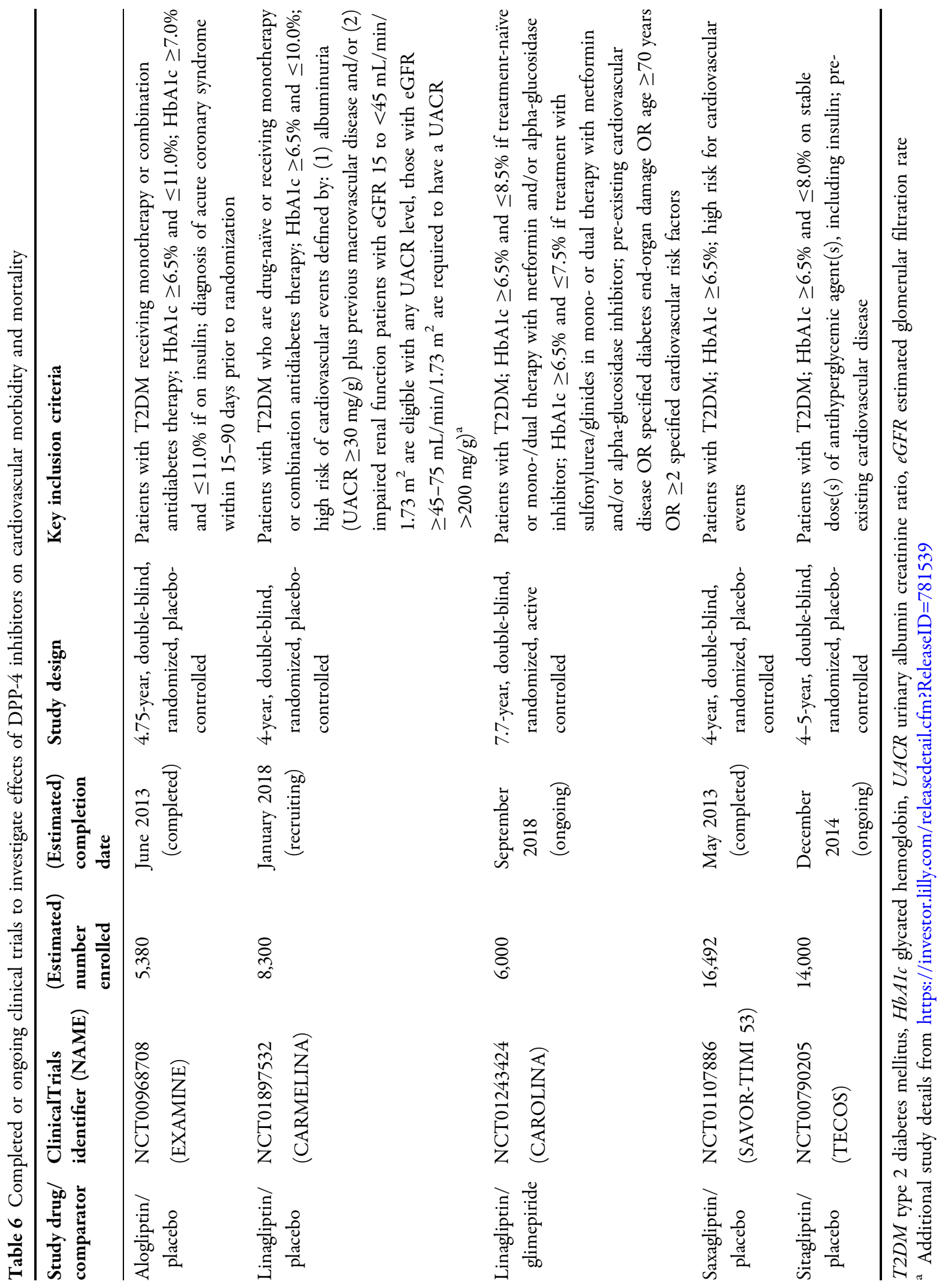


this population are underway or recently completed (Table 5), and their findings will provide further valuable safety and efficacy data about DPP-4 inhibitors in this group, and may also allow for additional pooled analyses of outcomes of interest such as fracture. Furthermore, ongoing cardiovascular safety trials with the DPP-4 inhibitors (see below and Table 6) are expected to include substantial numbers of elderly patients, providing valuable outcome information in this particular population. In particular, patients aged $\geq 70$ years qualify for inclusion in the CAROLINA (Cardiovascular Outcome Study of Linagliptin Versus Glimepiride in Patients With Type 2 Diabetes) trial, a largescale study that aims to investigate the effects of linagliptin on cardiovascular morbidity and mortality.

\section{Future Directions}

Safety data for DPP-4 inhibitors based on registration studies are reassuring, with various meta-analyses indicating a benign and perhaps beneficial cardiovascular safety profile for the class [92-96]. However, their long-term impact on cardiovascular outcomes has yet to be firmly established by clinical trials. To address this, several large-scale trials, including EXAMINE (Examination of Cardiovascular Outcomes with Alogliptin versus Standard of Care), CARMELINA (Cardiovascular and Renal Microvascular Outcome Study With Linagliptin in Patients With Type 2 Diabetes Mellitus at High Vascular Risk), CAROLINA, SAVOR-TIMI 53 (The Saxagliptin Assessment of Vascular Outcomes Recorded in Patients with Diabetes MellitusThrombolysis in Myocardial Infarction 53 trial), and TECOS (Sitagliptin Cardiovascular Outcome Study), have been designed to investigate the effects of DPP-4 inhibitors on cardiovascular morbidity and mortality (Table 6), and provide further insight into the efficacy, safety, and durability of response of these drugs. Results from the first two completed trials, EXAMINE and SAVOR-TIMI 53 , demonstrated no change in the risk of the composite major adverse cardiovascular event endpoint with either alogliptin or saxagliptin compared with placebo when added to the standard of care $[97,98]$. In EXAMINE, the point estimate for the hazard ratio (HR) was $<1$ and the upper limit of the $95 \%$ CI was $<1.3$, which was the pre-specified non-inferiority safety margin (HR with alogliptin, 0.96; upper boundary of the one-sided repeated CI, 1.16; $P<0.001$ for non-inferiority) [97]. Similarly in SAVOR-TIMI 53, saxagliptin met the noninferiority criterion but did not demonstrate cardiovascular superiority versus placebo (HR with saxagliptin 1.00, 95\% CI 0.89-1.12, $P=0.99$ for superiority, $P<0.001$ for noninferiority) [98].

\section{CONCLUSIONS}

The DPP-4 inhibitors are clearly emerging as a useful treatment option in the general T2DM population and, as additional trials are reported, it appears their characteristics may make them particularly suitable for more vulnerable patient populations. DPP-4 inhibitors can be used in the context of CKD, a significant consideration for any antidiabetes treatment. They are also weight neutral, an important aspect when making therapy choices with a patient who is overweight or obese. Furthermore, their straightforward dosing and low risk of hypoglycemia are desirable characteristics, particularly when choosing treatments for older patients. 
For various reasons, physicians may be cautious about using new therapies in vulnerable patient populations. However, these groups could potentially benefit from new treatments, and caution can be balanced by close monitoring and vigilance to ensure that all groups benefit from therapeutic advances. Given the variable progression of T2DM and the heterogeneity even within subgroups of patients, individualizing therapy will always be essential. Nevertheless, awareness of the typical issues for these high-risk groups may help physicians who are considering therapeutic options, including the DPP-4 inhibitors, when developing specific management strategies for individual patients.

\section{ACKNOWLEDGMENTS}

The article processing charges were paid by Boehringer Ingelheim. Medical writing assistance, supported financially by Boehringer Ingelheim, was provided by Ann Kerrigan of Envision Scientific Solutions during the preparation of this review. Boehringer Ingelheim was given the opportunity to check the data used in the manuscript for factual accuracy only. The author was fully responsible for all content and editorial decisions, was involved at all stages of manuscript development, and has approved the final version of the review that reflects the author's interpretation and conclusions.

Dr. Kountz is the guarantor for this article, and takes responsibility for the integrity of the work as a whole.

Conflict of interest. Dr. Kountz has received funding support for research from Medtronic.

Compliance with ethics guidelines. The analysis in this article is based on previously conducted studies, and does not involve any new studies of human or animal subjects performed by any of the authors.

Open Access. This article is distributed under the terms of the Creative Commons Attribution Noncommercial License which permits any noncommercial use, distribution, and reproduction in any medium, provided the original author(s) and the source are credited.

\section{REFERENCES}

1. Centers for Disease Control and Prevention (CDC). National diabetes fact sheet: national estimates and general information on diabetes and prediabetes in the United States; 2011. Atlanta: U.S. Department of Health and Human Services, Centers for Disease Control and Prevention 2011.

2. American Diabetes Association (ADA). Standards of medical care in diabetes-2013. Diabetes Care. 2013;36(Suppl 1):S11-66.

3. Handelsman Y, Mechanick JI, Blonde L, et al. American Association of Clinical Endocrinologists Medical Guidelines for Clinical Practice for developing a diabetes mellitus comprehensive care plan. Endocr Pract. 2011;17(Suppl 2):1-53.

4. Garber AJ, Abrahamson MJ, Barzilay JI, et al. American Association of Clinical Endocrinologists' comprehensive diabetes management algorithm 2013 consensus statement-executive summary. Endocr Pract. 2013;19:536-57.

5. Stark Casagrande S, Fradkin JE, Saydah SH, Rust KF, Cowie CC. The prevalence of meeting A1C, blood pressure, and LDL goals among people with diabetes, 1988-2010. Diabetes Care. 2013;36:2271-9.

6. Rodriguez A, Calle A, Vazquez L, Chacon F, Polavieja $\mathrm{P}$, Reviriego J. Blood glucose control and quality of health care in non-insulin-treated patients with Type 2 diabetes in Spain: a retrospective and cross-sectional observational study. Diabet Med. 2011;28:731-40.

7. Chan JC, Gagliardino JJ, Baik SH, et al. Multifaceted determinants for achieving glycemic control: the International Diabetes Management Practice Study (IDMPS). Diabetes Care. 2009;32:227-33.

8. Yu NC, Su HY, Chiou ST, et al. Trends of ABC control 2006-2011: a National Survey of Diabetes 
Health Promotion Institutes in Taiwan. Diabetes Res Clin Pract. 2013;99:112-9.

9. Mentis N, Vardarli I, Kothe LD, et al. GIP does not potentiate the antidiabetic effects of GLP-1 in hyperglycemic patients with type 2 diabetes. Diabetes. 2011;60:1270-6.

10. Holst JJ. The physiology of glucagon-like peptide 1 . Physiol Rev. 2007;87:1409-39.

11. Scheen AJ. DPP-4 inhibitors in the management of type 2 diabetes: a critical review of head-to-head trials. Diabetes Metab. 2012;38:89-101.

12. Inzucchi SE, Bergenstal RM, Buse JB, et al. Management of hyperglycemia in type 2 diabetes: a patient-centered approach: position statement of the American Diabetes Association (ADA) and the European Association for the Study of Diabetes (EASD). Diabetes Care. 2012;35:1364-79.

13. International Diabetes Federation (IDF) Clinical Guidelines Taskforce. Global guideline for type 2 diabetes. http://www.idf.org/sites/default/files/IDFGuideline-for-Type-2-Diabetes.pdf (Accessed 25 Oct 2013).

14. Centre for Clinical Practice at National Institute for Health and Clinical Excellence (NICE). Type 2 diabetes: newer agents for blood glucose control in type 2 diabetes. http://www.ncbi.nlm.nih.gov/ pubmed/22220323 (Accessed 25 Oct 2013).

15. US Department of Veterans Affairs (VA) and Department of Defense (DoD). VA/DoD clinical practice guideline for the management of diabetes mellitus. http://www.healthquality.va.gov/diabetes/ DM2010_FUL-v4e.pdf (Accessed 25 Oct 2013).

16. Shaya FT, Gbarayor CM, Huiwen Keri Y, AgyemanDuah M, Saunders E. A perspective on African American participation in clinical trials. Contemp Clin Trials. 2007;28:213-7.

17. Wright JT Jr, Bakris G, Greene T, et al. Effect of blood pressure lowering and antihypertensive drug class on progression of hypertensive kidney disease: results from the AASK trial. JAMA. 2002;288: 2421-31.

18. K/DOQI clinical practice guidelines for chronic kidney disease: evaluation, classification, and stratification. Am J Kidney Dis. 2002;39:S1-266.

19. Koro CE, Lee BH, Bowlin SJ. Antidiabetic medication use and prevalence of chronic kidney disease among patients with type 2 diabetes mellitus in the United States. Clin Ther. 2009;31:2608-17.

20. Plantinga LC, Crews DC, Coresh J, et al. Prevalence of chronic kidney disease in US adults with undiagnosed diabetes or prediabetes. Clin J Am Soc Nephrol. 2010;5:673-82.

21. US Renal Data System. USRDS 2012 Annual Data Report: atlas of chronic kidney disease and endstage renal disease in the United States. Bethesda: National Insititute of Health, National Institute of Diabetes and Digestive and Kidney Diseases; 2012.

22. Bristol-Myers Squibb Company. Glucophage ${ }^{\circledR}$ (metformin hydrochloride) Tablets, Glucophage ${ }^{\circledR}$ XR (metformin hydrochloride) extended-release tablets. http://packageinserts.bms.com/pi/pi_gluco phage.pdf (Accessed 25 Oct 2013).

23. National Kidney Foundation. KDOQI clinical practice guideline for diabetes and CKD: 2012 update. Am J Kidney Dis. 2012;60:850-86.

24. Pratley RE, Salsali A. Inhibition of DPP-4: a new therapeutic approach for the treatment of type 2 diabetes. Curr Med Res Opin. 2007;23:919-31.

25. Bergman AJ, Cote J, Yi B, et al. Effect of renal insufficiency on the pharmacokinetics of sitagliptin, a dipeptidyl peptidase- 4 inhibitor. Diabetes Care. 2007;30:1862-4.

26. Boulton DW, Li L, Frevert EU, et al. Influence of renal or hepatic impairment on the pharmacokinetics of saxagliptin. Clin Pharmacokinet. 2011;50:253-65.

27. Graefe-Mody U, Friedrich C, Port A, et al. Effect of renal impairment on the pharmacokinetics of the dipeptidyl peptidase-4 inhibitor linagliptin. Diabetes Obes Metab. 2011;13:939-46.

28. Ito $M$, Abe $M$, Okada $K$, et al. The dipeptidyl peptidase-4 (DPP-4) inhibitor vildagliptin improves glycemic control in type 2 diabetic patients undergoing hemodialysis. Endocr J. 2011;58: 979-87.

29. McGill JB, Sloan L, Newman J, et al. Long-term efficacy and safety of linagliptin in patients with type 2 diabetes and severe renal impairment: a 1-year, randomized, double-blind, placebocontrolled study. Diabetes Care. 2013;36:237-44.

30. Nowicki M, Rychlik I, Haller H, Warren ML, Suchower L, Gause-Nilsson I. Saxagliptin improves glycaemic control and is well tolerated in patients with type 2 diabetes mellitus and renal impairment. Diabetes Obes Metab. 2011;13:523-32.

31. Nowicki M, Rychlik I, Haller $\mathrm{H}$, et al. Long-term treatment with the dipeptidyl peptidase- 4 inhibitor saxagliptin in patients with type 2 diabetes mellitus and renal impairment: a randomised controlled 52-week efficacy and safety study. Int J Clin Pract. 2011;65:1230-9. 
32. Chan JC, Scott R, Arjona Ferreira JC, et al. Safety and efficacy of sitagliptin in patients with type 2 diabetes and chronic renal insufficiency. Diabetes Obes Metab. 2008;10:545-55.

33. Arjona Ferreira JC, Marre M, Barzilai N, et al. Efficacy and safety of sitagliptin versus glipizide in patients with type 2 diabetes and moderate-tosevere chronic renal insufficiency. Diabetes Care. 2013;36:1067-73.

34. Arjona Ferreira JC, Corry D, Mogensen CE, et al. Efficacy and safety of sitagliptin in patients with type 2 diabetes and ESRD receiving dialysis: a 54-week randomized trial. Am J Kidney Dis. 2013;61:579-87.

35. Lukashevich V, Schweizer A, Shao Q, Groop PH, Kothny W. Safety and efficacy of vildagliptin versus placebo in patients with type 2 diabetes and moderate or severe renal impairment: a prospective 24-week randomized placebo-controlled trial. Diabetes Obes Metab. 2011;13:947-54.

36. Kothny W, Shao Q, Groop PH, Lukashevich V. Oneyear safety, tolerability and efficacy of vildagliptin in patients with type 2 diabetes and moderate or severe renal impairment. Diabetes Obes Metab. 2012;14:1032-9.

37. Takeda Pharmaceuticals America, Inc. Nesina (alogliptin) tablets [package insert]. http://www. takeda.us/products/ (Accessed 25 Oct 2013).

38. Boehringer Ingelheim International GmbH. Tradjenta $^{\circledR}$ (linagliptin) tablets [package insert]. http://bidocs.boehringer-ingelheim.com/BIWebAccess/ ViewServlet.ser?docBase=renetnt\&folderPath=/Prescrib ing+Information/PIs/Tradjenta/Tradjenta.pdf (Accessed 25 Oct 2013).

39. Bristol-Myers Squibb Company. ONGLYZA ${ }^{\circledR}$ (saxagliptin) tablets [package insert]. http:// packageinserts.bms.com/pi/pi_onglyza.pdf (Accessed 25 Oct 2013).

40. Merck Sharp \& Dohme Corp. Januvia ${ }^{\circledR}$ (sitagliptin) tablets [package insert]. http://www.merck.com/ product/usa/pi_circulars/j/januvia/januvia_pi.pdf (Accessed 25 Oct 2013).

41. Novartis Europharm Ltd. Galvus ${ }^{\circledR}$ (vildagliptin) tablets [package insert]. http://www.ema.europa. eu/docs/en_GB/document_library/EPAR_-_Product_ Information/human/000771/WC500020327.pdf (Accessed 25 Oct 2013).

42. Brown NJ, Byiers S, Carr D, Maldonado M, Warner BA. Dipeptidyl peptidase-IV inhibitor use associated with increased risk of ACE inhibitorassociated angioedema. Hypertension. 2009;54: 516-23.
43. Byrd JS, Minor DS, Elsayed R, Marshall GD. DPP-4 inhibitors and angioedema: a cause for concern? Ann Allergy Asthma Immunol. 2011;106:436-8.

44. Tornio A, Niemi M, Neuvonen PJ, Backman JT. Drug interactions with oral antidiabetic agents: pharmacokinetic mechanisms and clinical implications. Trends Pharmacol Sci. 2012;33:312-22.

45. Cheung BM, Ong KL, Cherny SS, Sham PC, Tso AW, Lam KS. Diabetes prevalence and therapeutic target achievement in the United States, 1999 to 2006. Am J Med. 2009;122:443-53.

46. Chin $\mathrm{MH}$, Zhang JX, Merrell K. Diabetes in the African-American Medicare population. Morbidity, quality of care, and resource utilization. Diabetes Care. 1998;21:1090-5.

47. Gu K, Cowie CC, Harris MI. Mortality in adults with and without diabetes in a national cohort of the U.S. population, 1971-1993. Diabetes Care. 1998;21:1138-45.

48. Young BA, Maynard C, Reiber G, Boyko EJ. Effects of ethnicity and nephropathy on lower-extremity amputation risk among diabetic veterans. Diabetes Care. 2003;26:495-501.

49. Young BA, Maynard C, Boyko EJ. Racial differences in diabetic nephropathy, cardiovascular disease, and mortality in a national population of veterans. Diabetes Care. 2003;26:2392-9.

50. Marshall MC Jr. Diabetes in African Americans. Postgrad Med J. 2005;81:734-40.

51. Dagogo-Jack S. Ethnic disparities in type 2 diabetes: pathophysiology and implications for prevention and management. J Natl Med Assoc. 2003;95(774): 9-89.

52. Higgins PB, Férnández JR, Garvey WT, Granger WM, Gower BA. Entero-insular axis and postprandial insulin differences in African American and European American children. Am J Clin Nutr. 2008;88:1277-83.

53. Velasquez-Mieyer PA, Cowan PA, Pérez-Faustinelli $S$, et al. Racial disparity in glucagon-like peptide 1 and inflammation markers among severely obese adolescents. Diabetes Care. 2008;31:770-5.

54. Velasquez-Mieyer PA, Cowan PA, Umpierrez GE, Lustig RH, Cashion AK, Burghen GA. Racial differences in glucagon-like peptide-1 (GLP-1) concentrations and insulin dynamics during oral glucose tolerance test in obese subjects. Int J Obes Relat Metab Disord. 2003;27:1359-64.

55. Flegal KM, Carroll MD, Kit BK, Ogden CL. Prevalence of obesity and trends in the 
distribution of body mass index among US adults, 1999-2010. JAMA. 2012;307:491-7.

56. Muntner P, Newsome B, Kramer H, et al. Racial differences in the incidence of chronic kidney disease. Clin J Am Soc Nephrol. 2012;7:101-7.

57. Peralta CA, Katz R, DeBoer I, et al. Racial and ethnic differences in kidney function decline among persons without chronic kidney disease. J Am Soc Nephrol. 2011;22:1327-34.

58. Kirk JK, D'Agostino RB Jr, Bell RA, et al. Disparities in HbA1c levels between African-American and non-Hispanic white adults with diabetes: a metaanalysis. Diabetes Care. 2006;29:2130-6.

59. Aroda VR, Henry RR, Han J, et al. Efficacy of GLP-1 receptor agonists and DPP-4 inhibitors: metaanalysis and systematic review. Clin Ther. 2012;34(1247-58):e22.

60. DeFronzo RA, Stonehouse AH, Han J, Wintle ME. Relationship of baseline HbA1c and efficacy of current glucose-lowering therapies: a meta-analysis of randomized clinical trials. Diabet Med. 2010;27: 309-17.

61. Friedrich C, Glund S, Lionetti D, et al. Pharmacokinetic and pharmacodynamic evaluation of linagliptin in African American patients with type 2 diabetes mellitus. Br J Clin Pharmacol. 2013;76: 445-54.

62. Thrasher J, Daniels K, Patel S, Whetteckey J. Black/ African American patients with type 2 diabetes mellitus: study design and baseline patient characteristics from a randomized clinical trial of linagliptin. Expert Opin Pharmacother. 2012;13: 2443-52.

63. Thrasher J, Daniels K, Patel S, Whetteckey J, Woerle HJ. Efficacy and safety of linaglipin in Black/African American patients with type 2 diabetes: a 6 month, randomized, double-blind, placebo-controlled study. Endocr Pract. 2013 (in press).

64. U.S. Census Bureau. Annual estimates of the resident population for selected age groups by sex for the United States: April 1, 2010 to July 1, 2011 (NC-EST2011-02). http://www.census.gov/popest/ data/national/asrh/2011/index.html (Accessed 25 Oct 2013).

65. U.S. Census Bureau. Projections of the population by selected age group and sex for the United States: 2010 to 2050. http://www.census.gov/population/ projections/data/national/2008/summarytables.html (Accessed 25 Oct 2013).

66. Dailey G, Kim MS, Lian JF. Patient compliance and persistence with antihyperglycemic drug regimens: evaluation of a medicaid patient population with type 2 diabetes mellitus. Clin Ther. 2001;23: 1311-20.

67. Dailey G, Kim MS, Lian JF. Patient compliance and persistence with anti-hyperglycemic therapy: evaluation of a population of type 2 diabetic patients. J Int Med Res. 2002;30:71-9.

68. Donnan PT, MacDonald TM, Morris AD. Adherence to prescribed oral hypoglycaemic medication in a population of patients with Type 2 diabetes: a retrospective cohort study. Diabet Med. 2002;19: 279-84.

69. Sinclair A, Morley JE, Rodriguez-Mañas L, et al. Diabetes mellitus in older people: position statement on behalf of the International Association of Gerontology and Geriatrics (IAGG), the European Diabetes Working Party for Older People (EDWPOP), and the International Task Force of Experts in Diabetes. J Am Med Dir Assoc. 2012;13:497-502.

70. Kirkman MS, Briscoe VJ, Clark N, et al. Diabetes in older adults. Diabetes Care. 2012;35:2650-64.

71. Schweizer A, Dejager S, Bosi E. Comparison of vildagliptin and metformin monotherapy in elderly patients with type 2 diabetes: a 24-week, doubleblind, randomized trial. Diabetes Obes Metab. 2009;11:804-12.

72. Barzilai N, Guo H, Mahoney EM, et al. Efficacy and tolerability of sitagliptin monotherapy in elderly patients with type 2 diabetes: a randomized, double-blind, placebo-controlled trial. Curr Med Res Opin. 2011;27:1049-58.

73. Barnett $\mathrm{AH}$, Huisman $\mathrm{H}$, Jones $\mathrm{R}$, von Eynatten $\mathrm{M}$, Patel S, Woerle HJ. Linagliptin for patients aged 70 years or older with type 2 diabetes inadequately controlled with common antidiabetes treatments: a randomised, double-blind, placebo-controlled trial. Lancet. 2013;382:1413-23.

74. Schernthaner G, Barnett AH, Emser A, et al. Safety and tolerability of linagliptin: a pooled analysis of data from randomized controlled trials in 3572 patients with type 2 diabetes mellitus. Diabetes Obes Metab. 2012;14:470-8.

75. Schweizer A, Dejager S, Foley JE, Shao Q, Kothny W. Clinical experience with vildagliptin in the management of type 2 diabetes in a patient population $\geq 75$ years: a pooled analysis from a database of clinical trials. Diabetes Obes Metab. 2011;13:55-64.

76. Pratley RE, Rosenstock J, Pi-Sunyer FX, et al. Management of type 2 diabetes in treatment-naive elderly patients: benefits and risks of vildagliptin monotherapy. Diabetes Care. 2007;30:3017-22. 
77. Pratley RE, McCall T, Fleck PR, Wilson CA, Mekki Q. Alogliptin use in elderly people: a pooled analysis from phase 2 and 3 studies. J Am Geriatr Soc. 2009;57:2011-9.

78. Doucet J, Chacra A, Maheux P, Lu J, Harris S, Rosenstock J. Efficacy and safety of saxagliptin in older patients with type 2 diabetes mellitus. Curr Med Res Opin. 2011;27:863-9.

79. Schwartz SL. Treatment of elderly patients with type 2 diabetes mellitus: a systematic review of the benefits and risks of dipeptidyl peptidase- 4 inhibitors. Am J Geriatr Pharmacother. 2010;8: 405-18.

80. Patel S, Schernthaner G, Barnett AH, Emser A, von Eynatten M, Woerle H-J. Safety and efficacy of linagliptin in elderly patients with type 2 diabetes: evidence from 1331 individuals aged $\geq 65$ years. Diabetologia. 2012;55(Suppl 1):s531.

81. Woerle H-J, Neubacher D, Patel S, von Eynatten M. Safety and efficacy of linagliptin plus basal insulin combination therapy in a vulnerable population of elderly patients (age $\geq 70$ years) with type 2 diabetes. Diabetologia. 2012;55(Suppl 1):s350.

82. Gooßen K, Gräber S. Longer term safety of dipeptidyl peptidase-4 inhibitors in patients with type 2 diabetes mellitus: systematic review and meta-analysis. Diabetes Obes Metab. 2012;14: 1061-72.

83. Karasik A, Aschner P, Katzeff H, Davies MJ, Stein PP. Sitagliptin, a DPP-4 inhibitor for the treatment of patients with type 2 diabetes: a review of recent clinical trials. Curr Med Res Opin. 2008;24:489-96.

84. Monami M, Dicembrini I, Antenore A, Mannucci E. Dipeptidyl peptidase-4 inhibitors and bone fractures: a meta-analysis of randomized clinical trials. Diabetes Care. 2011;34:2474-6.

85. Giangregorio LM, Leslie WD, Lix LM, et al. FRAX underestimates fracture risk in patients with diabetes. J Bone Miner Res. 2012;27:301-8.

86. Schwartz AV, Vittinghoff E, Bauer DC, et al. Association of BMD and FRAX score with risk of fracture in older adults with type 2 diabetes. JAMA. 2011;305:2184-92.

87. Janghorbani M, Van Dam RM, Willett WC, Hu FB. Systematic review of type 1 and type 2 diabetes mellitus and risk of fracture. Am J Epidemiol. 2007;166:495-505.
88. Vestergaard P. Discrepancies in bone mineral density and fracture risk in patients with type 1 and type 2 diabetes-a meta-analysis. Osteoporos Int. 2007;18:427-44.

89. Gallwitz B, Rosenstock J, Rauch T, et al. 2-year efficacy and safety of linagliptin compared with glimepiride in patients with type 2 diabetes inadequately controlled on metformin: a randomised, double-blind, noninferiority trial. Lancet. 2012;380:475-83.

90. Emerging Risk Factors Collaboration, Sarwar N, Gao $P$, et al. Diabetes mellitus, fasting blood glucose concentration, and risk of vascular disease: a collaborative meta-analysis of 102 prospective studies. Lancet. 2010;375:2215-22.

91. Banerjee C, Moon YP, Paik MC, et al. Duration of diabetes and risk of ischemic stroke: the Northern Manhattan Study. Stroke. 2012;43:1212-7.

92. Williams-Herman D, Engel SS, Round E, et al. Safety and tolerability of sitagliptin in clinical studies: a pooled analysis of data from 10,246 patients with type 2 diabetes. BMC Endocr Disord. 2010;10:7.

93. Frederich R, Alexander JH, Fiedorek FT, et al. A systematic assessment of cardiovascular outcomes in the saxagliptin drug development program for type 2 diabetes. Postgrad Med. 2010;122:16-27.

94. Schweizer A, Dejager S, Foley JE, Couturier A, Ligueros-Saylan M, Kothny W. Assessing the cardio-cerebrovascular safety of vildagliptin: metaanalysis of adjudicated events from a large Phase III type 2 diabetes population. Diabetes Obes Metab. 2010;12:485-94.

95. Johansen OE, Neubacher D, von Eynatten M, Patel S, Woerle HJ. Cardiovascular safety with linagliptin in patients with type 2 diabetes mellitus: a pre-specified, prospective, and adjudicated meta-analysis of a phase 3 programme. Cardiovasc Diabetol. 2012;11:3.

96. Monami M, Dicembrini I, Martelli D, Mannucci E. Safety of dipeptidyl peptidase- 4 inhibitors: a metaanalysis of randomized clinical trials. Curr Med Res Opin. 2011;27(Suppl 3):57-64.

97. White WB, Cannon CP, Heller SR, et al. Alogliptin after acute coronary syndrome in patients with type 2 diabetes. N Engl J Med. 2013;369:1327-35.

98. Scirica BM, Bhatt DL, Braunwald E, et al. Saxagliptin and cardiovascular outcomes in patients with type 2 diabetes mellitus. N Engl J Med. 2013;369: 1317-26. 